\title{
Development of Product Data Model for Maintenance in Concrete Highway Bridges
}

\author{
Satoshi Kubota and Ichizou Mikami \\ Faculty of Environmental and Urban Engineering, Kansai University, 3-3-35 Yamate-cho, Suita-shi, Osaka 564-8680, Japan \\ Correspondence should be addressed to Satoshi Kubota; skubota@kansai-u.ac.jp
}

Received 14 September 2012; Revised 27 June 2013; Accepted 27 July 2013

Academic Editor: Hitoshi Furuta

Copyright ( $) 2013$ S. Kubota and I. Mikami. This is an open access article distributed under the Creative Commons Attribution License, which permits unrestricted use, distribution, and reproduction in any medium, provided the original work is properly cited.

The primary objective of this paper is to develop the product data models, in which systematic information is defined for accumulating, exchanging, and sharing in the maintenance of concrete highway bridges. The information requirement and existing issues and solutions were analyzed based on the life cycle and the standardization for sharing. The member data models and business data models that defined design and construction information and accumulated results information were developed. The maintenance business process in which project participants utilize the product data model was described as utilization scenario. The utilization frameworks which define information flow were developed.

\section{Introduction}

Concrete highway bridges undertake important roles in civil infrastructures and should be used in safety and kept in good condition. For maintaining, repairing, and rehabilitating the concrete highway bridges, maintenance management should be carried out effectively $[1,2]$. In maintenance process of concrete highway bridges, it is important that the maintenance process is effective and the quality of inspection is secured. The cost-effective and quality maintenance is dependent on reliable inspection and condition assessment information [3]. The reliable maintenance information influences bridge management system (BMS) $[4,5]$. BMS does not use the standardized information and cannot exchange, share, and reutilize the information. The maintenance information should be standardized and is needed for cost-effective business process model. Modeling standardizes the information. The process model for utilizing the standardized information should be constructed.

The primary objective of this paper is to develop product data models as a framework for exchanging, sharing, and utilizing the maintenance information in concrete highway bridges maintenance. This paper targets concrete highway bridge and does not target railroad and pedestrian bridge. Product data models for maintenance are developed for standardizing the various maintenance data. Business process model for maintenance is constructed for maintaining the concrete highway bridges. For developing the product data models and process model, the existing maintenance processes and information [6-9] are analyzed. The analyzed results are used for modeling the as-built process and product data. The required functions are analyzed and described for product and process models by use-case diagram in Unified Modeling Language (UML). The product data models consisted of member and business data models and described the maintenance information by using the class diagram. The member data models describe the members of concrete highway bridges. The business data models describe the input and output information of inspection and condition assessment. The maintenance information is standardized and defined by information schema in Extensible Markup Language (XML). The product data models are utilized in utilization platform for efficiency of maintenance business and utilization of information. The product data models are useful for exchanging, storing, and utilizing the standardized maintenance information. Business process is modeled by analyzing maintenance flow. The modeled process is based on the idea of project management and preventive maintenance. The product data models are utilized in business process. The process model is evaluated for validating the efficiency and quality 


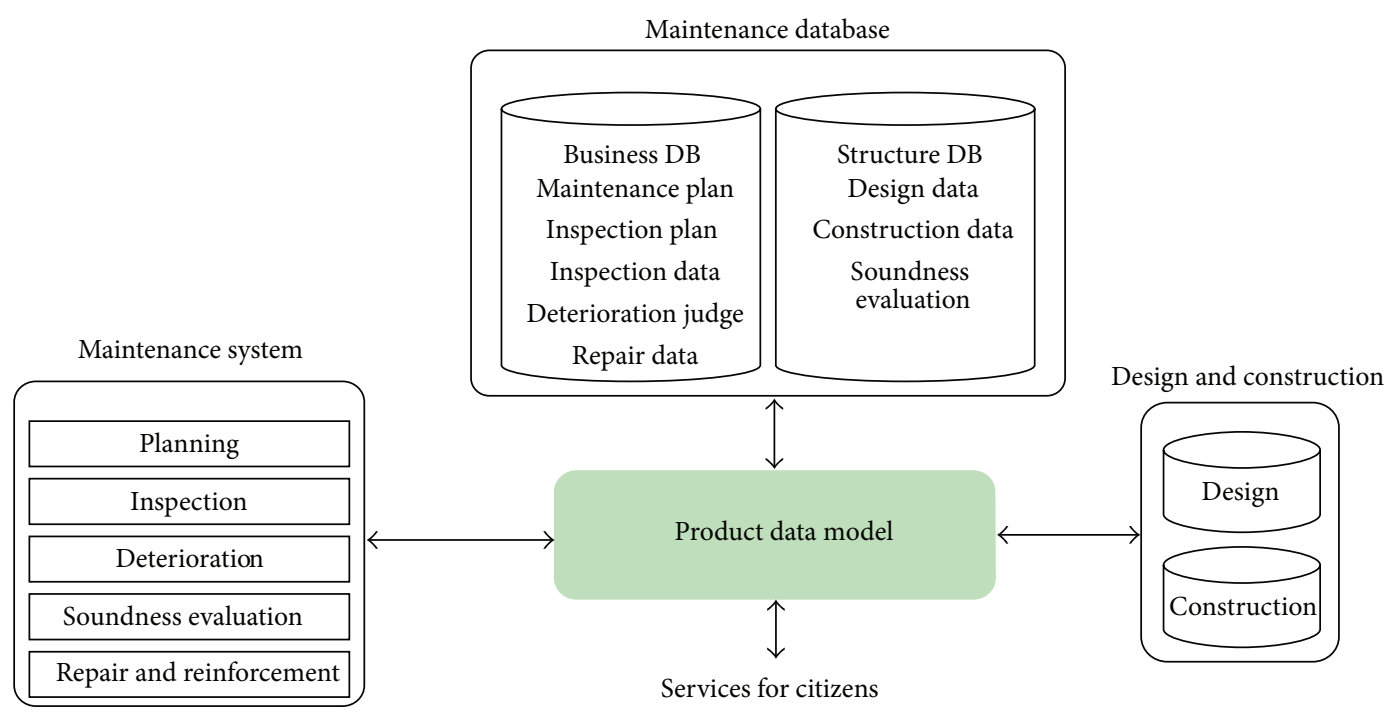

FIGURE 1: The concept of model oriented management system.

accuracy. The maintenance engineers can maintain the concrete highway bridges by following the proposed product and utilization models.

\section{State of the Art for Product Data Model}

Product data models of social infrastructure facilities are made by various organizations and research institutions [1016]. In International Organization for Standardization (ISO), STEP (Standard for the Exchange of Product model data) was standardized for representing product model data. STEPbased bridge product data model have been constructed [1721]. They represented three-dimensional data of bridges and other civil infrastructures using STEP AP203 and XML. IFC bridge was developed by integrating J-IFC-BRIDGE, which is a combination of prestressed concrete bridge product data model, YLPC-BRIDGE, and steel girder bridge product data model, YLSG-BRIDGE, and IFC-BRIDGE, which has been developed in France [22] (Yabuki et al., 2006). CityGML is the official Open Geospatial Consortium (OGC) standard for the modeling and exchange of virtual 3D city and landscape models. CityGML bridge module represents the thematic and spatial aspects of bridges, its aggregation in parts and construction elements in four levels of detail [23].

The application areas of three-dimensional and fourdimensional models can be grouped according to the three major phases in which such models have been used the shaping phase, the design phase, and the construction phase [24]. Practitioners can use three-dimensional models of designs with complex geometry during meetings and other discussions to convey information about issues that would be difficult to make clear using conventional two-dimensional drawings. Engineers would be able use three-dimensional models not only for virtually reviewing the design of a facility, but also for analyzing building operations and performance. Technology for utilizing four-dimensional information has the potential to facilitate the visual presentation of ideas to project participants in order to promote understanding and improve operations [25]. Staub-French and Khanzode note that research efforts have substantially increased and demonstrate that approaches using four-dimensional information are now being applied to address the complex challenges of construction [26]. Koo and Fischer developed a four-dimensional Computer Aided Design (CAD) model for a commercial construction project and concluded that the model sped their understanding of the schedule and identification of potential problems [27]. Park et al. show that threedimensional and four-dimensional CADs can be applied to life-cycle facility management [28]. Researchers have positively evaluated the effectiveness of three-dimensional and four-dimensional models within different educational and industrial contexts. In addition, practitioners have acknowledged the potential of these new technologies.

\section{Requirement of Product Data Models in Maintenance}

3.1. Maintenance Management System. In maintenance of concrete highway bridges, the management system with high accuracy is necessary, so analyzed information in life cycle should be accumulated. This system is used in each phase of design, construction, inspection, soundness evaluation, deterioration forecast, and maintenance plan. The database of system has the role to support the each stage of life cycle. For operating the management system, standardized information should be accumulated and shared based on product data models on considering a long-term service stage of concrete highway bridges. The concept of model oriented management system is shown in Figure 1. It is difficult to define the information unitary used in various existing systems and databases because of feasibility and operation. Standardized information can be exchanged and shared by exchanging the maintenance information through the product data models in maintenance management system and databases. 
3.2. Standardization of System Information. Product data models can be classified into two types: geometry data models and business data models. Geometry data models contain information associated with the constituent parts of concrete highway bridges. Business data models contain information necessary for maintenance management work, as well as the results of information analysis produced as the result of such work. Interoperability and compatibility are important for the exchange and sharing of information. It is, therefore, useful to define the rules of information exchange and sharing using existing standards and specifications. We propose the use of the following types of standards for defining road data model information.

(a) Business process standard: a business process standard is a rule related to business processes and the management and construction of information to be shared between companies and agencies. This includes standards related to business process, quality management, and project management.

(b) Information infrastructure standard: an information infrastructure standard is a standard related to the infrastructure of systems for exchanging and sharing information. This includes standards for middleware and platforms, operating systems, security, databases, communication networks, and information exchange media.

(c) Information sharing standard: an information sharing standard is a standard related to information which is exchanged and shared between companies and agencies. This includes requirements for information sharing systems and middleware, document structure, application system data, text data, and drawings.

\subsection{Required Elements in Life Cycle of Highway Bridges.} Requirements in product data models are analyzed for each phase in life cycle of concrete highway bridges, that is, design, construction, inspection, soundness evaluation, deterioration forecast, and maintenance plan.

In design stage, the initial conditions and state of concrete highway bridges are decided and have a large influence on maintenance stage. Therefore, concrete highway bridges should be designed for reducing the life-cycle costs. The design criterion is reviewed as needed. In construction stage, it is necessary to record and save the conditions of bridges with accuracy. The construction data shows the initial realities and is the important element becoming basis of soundness evaluation and deterioration forecast. The purpose of inspection is to understand the condition of concrete highway bridges. They are inspected for linking the inspection results from soundness evaluation and deterioration forecast to repair and reinforcement. In other words, it is necessary that the information is collected for decision making of deterioration forecast, deterioration measures, and measures time. It is hoped that the inspection results are recorded quantitatively and objectively with analysis and image information, and the consistent and effective data is recorded for soundness evaluation and deterioration forecast. In particular, the damages found as the results of inspection are continuously observed and should be accumulated and updated as consistent historical data from inspection to repair in a database. And, it is effective that maintenance project participants share these data.

For understanding the condition of concrete highway bridges, it is necessary that the methods of soundness evaluation are changed to the consistent methods based on objective inspection data accumulated in a database. As a result, the effectiveness of revision of design standards and change of maintenance methods can be pursued and verified.

Deterioration is distinguished by the one which it is necessary to forecast the state of future and the one which it is necessary to find the superficial stripping, falling of masonry, and so on in daily inspection. It is necessary to forecast deterioration theoretically based on knowledge and experience, to analogize and analyze deterioration based on hard data, and to forecast by combining these methods. Deterioration is forecasted theoretically by establishing forecast method based on research cases and analyzing collected existing inspection results and historical data of repair and reinforcement. It is necessary to share the accumulated data and the results of deterioration forecast among engineers of maintenance of concrete highway bridges.

The appropriate time and scale of repair and renewal should be judged, and the best repair and reinforcement should be selected based on the evaluated present state of concrete highway bridges properly and forecasted future state adequately for establishing the appropriate maintenance plan. However, the lack of data which shows that the effect of improvement by repair is one of causes of maintenance such as symptomatic therapy because maintenance data is not accumulated and shared.

\section{Development of Product Data Models}

4.1. Development Method of Product Data Models. It is difficult to standardize the existing data models to a unified format, and it is important to standardize required functions, classification, and items of product data model. The proposed method is shown in Figure 2 for standardizing the functions required to be fulfilled by the road data models, in addition to the types and items of information to be maintained. This method was developed after a survey and analysis of existing methods for constructing data models, under the assumption that the models will be applied to all social infrastructure facilities. The method of developing product data models is as follows.

(1) State objectives and assumptions: set the objective for constructing the data model. Establish the scope of work to be analyzed and any points to be emphasized, such as the reduction of work or the utilization of information in downstream processes. Clearly identify the target users, such as managers or contractors. Identify problem points with respect to the objectives and devise measures to solve these problem points. 


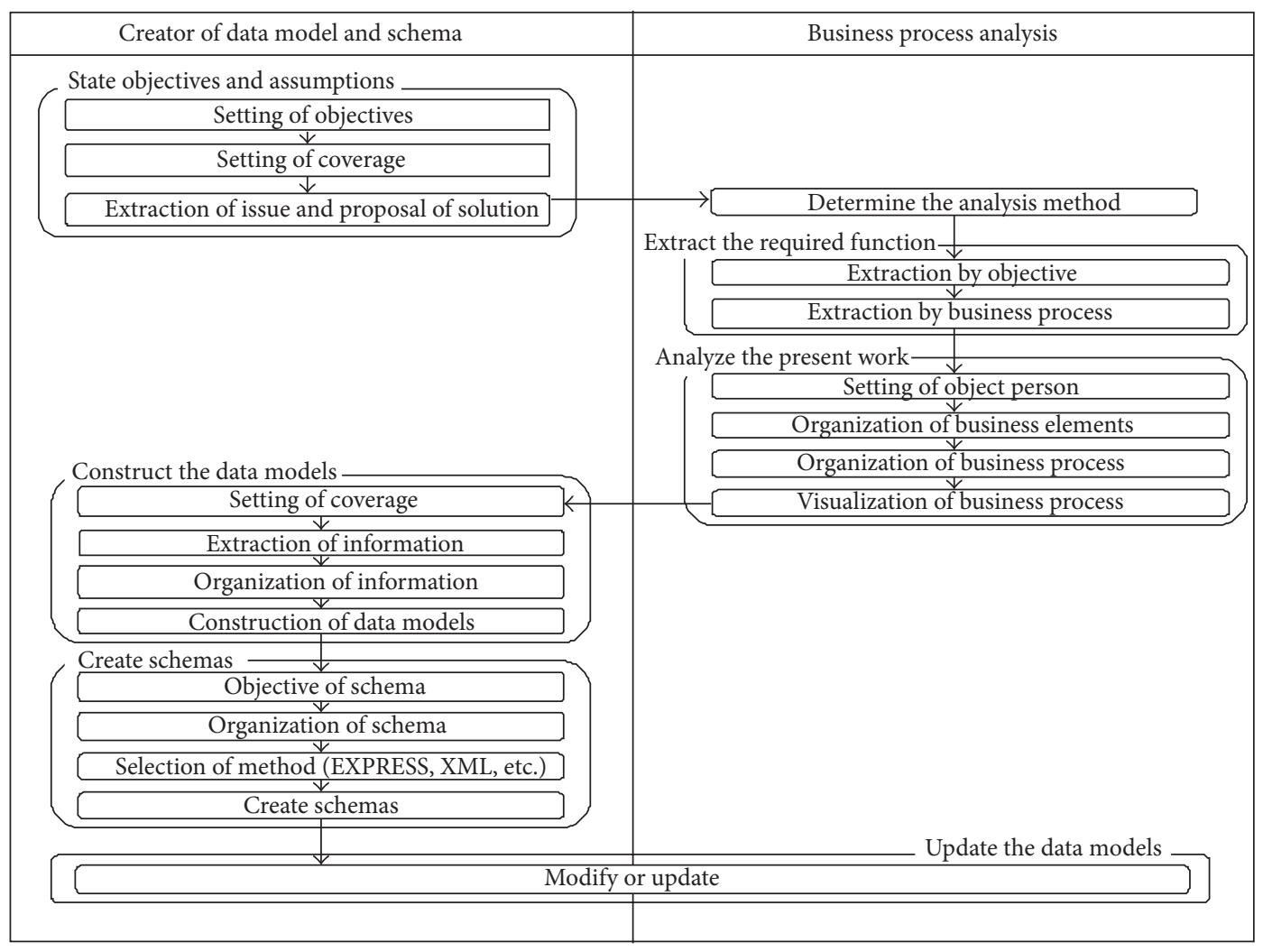

FIGURE 2: Method of constructing product data models.

(2) Determine the analysis method: determine an analysis method of modeling in order to arrange the methods that use the relevant work processes and information. Support tools for analyzing or reconstructing the present status of work include the Integrated Definition method (IDEF), EXPRESS-G (ISO10303: Industrial automation systems and integration-product data representation and exchange), and Unified Modeling Language (UML).

(3) Extract the required function: extract the required functions based on the perspective of those engaged in this type of work.

(4) Analyze the present work: identify the scope of the activities, the responsibilities of the organizations or managers of the system, and the arrangement of the work items. Arrange the workflow to encompass the work items and visualize the flow using the determined analysis method.

(5) Construct the data models: extract information of high importance based on the analysis of work processes. Arrange the information based on the determined analysis model and construct the data models. Verify the attributes of the created data models and the relationships between data models.

(6) Create schemas: set the objectives of creating schemas and determine the encoding method. Create schemas in accordance with the determined encoding method.
Verify whether the created schemas can be used in accordance with the objectives or not. Use XML or EXPRESS (ISO10303) to create the schemas.

(7) Update the data models: modify the data models as necessary to improve or amend them in response to changes or additional information.

4.2. Design Concepts of Product Data Model. Huge data and information are generated in maintenance stage of concrete highway bridges. If the information is defined as a unit model, there are problems that system that extracts unintended information and maintenance information cannot be used in maintenance operation. So, the maintenance information is classified into member and business information. The product data model of concrete highway bridges is composed of the member data model and the business data model. Member data model describes the members of concrete highway bridges. Business data model describes the input and output data of inspection, condition, assessment, and so on. The relation between models is shown in Figure 3.

Member data model is composed of design and construction information that is needed and accumulated for using in maintenance process. To such the composition, it is necessary to grasp structural types of members and information on members in maintenance plan, deterioration diagnosis, repair, and reinforcement stage. The member data model intends superstructure, substructure, and ancillary facilities composing girder bridge. The information of CAD, 


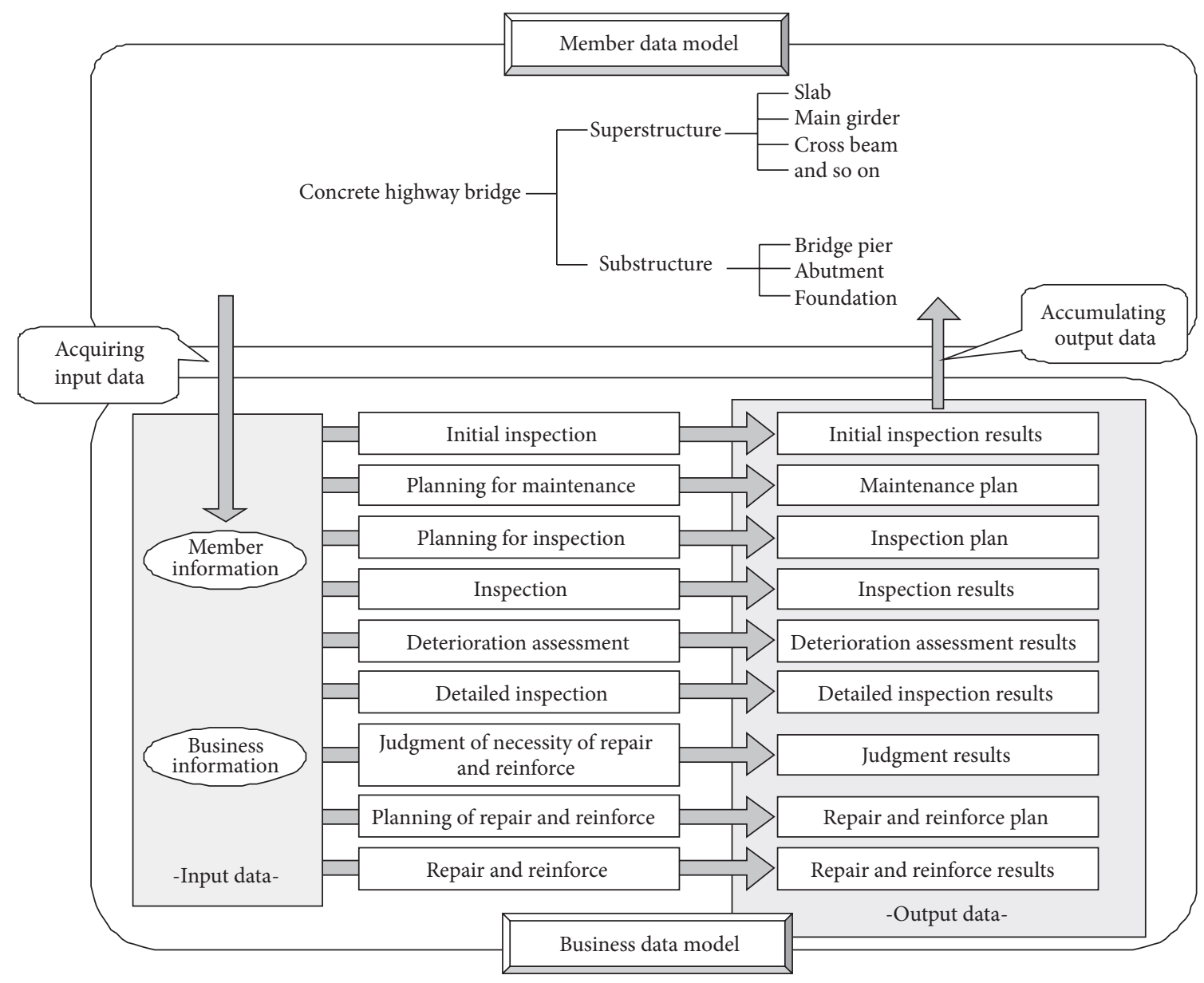

FIGURE 3: Relation between product data models.

design analysis, and quantity calculation results is added as meta data in the product data model. The meta data has the schema and whereabouts information.

Business data model is composed of input information used in operations and output information generated as the results of operations. In input information, the required functions are analyzed from the viewpoint of the use of information, cost reduction, and operations reduction. In output information, the required functions are analyzed from the viewpoint of soundness of members and grasp of deterioration condition.

Maintenance project participants use the defined information and accumulated information in member data model as input information. The output information is generated by defined format based on the businesses results. The generated information is accumulated in the member data model after inspection, diagnostication, and so on. Therefore, the past results can be utilized for the businesses in the future.

4.3. Analysis of As-Built Maintenance Process. The existing maintenance processes and information are analyzed for constructing the product data model. The analyzed results are used for modeling the as-is process and product data models. The as-is business process model was described by using activity diagram in UML. In this paper, it was analyzed maintenance process of the Ministry of Land, Infrastructure, and Transportation, Japan Highway Public Corporation, Metropolitan Expressway Public Corporation, and Hanshin Expressway Public Corporation. The as-is information flow was described by sequence diagram of UML. The following issues were analyzed, and the corresponding resolutions were reviewed.

(1) Issue: operations are overlapped.

Resolution: the roles of project participants are redefined.

(2) Issue: bridges are treated symptoms as damages appear.

Resolution: the preventive maintenance is adopted.

(3) Issue: deterioration information is not utilized.

Resolution: the inspection and condition assessment data are accumulated and utilized.

4.4. Construction of Member Data Models. Maintenance project participants are redefined in agency, project manager, inspection companies, and repair/reinforcement companies. Required functions of product data models are extracted for 
the purpose of reduction of maintenance costs, securement of permanence, and long lifetime. And, they are extracted for operating the maintenance and utilizing the results information with agencies, bridge managers, inspection companies, repair companies, and reinforcement companies. The required functions in bridge manager are shown in Figure 4. They are "reduction of budget" and "long lifetime" for costs reduction, "securement permanence" for using in safety, and "deterioration forecast of the material," "keeping the product quality of members," "keeping the product quality of inspection," and "usage of the technology of long lifetime" for comprehending the members soundness. Similarly, the required functions were extracted in inspection companies and repair/reinforcement companies.

A data model in inspection plan is shown in Figure 5 by class diagram of UML. The information is extracted, that flowed to maintenance stage after design and construction stage, and accumulated for future maintenance businesses. The information is accumulated for comprehending the deterioration condition in planning of maintenance and inspection and for referring to the past assessment results in deterioration assessment and judgment for soundness. The soundness information has the damage lank and deterioration condition and is defined and modeled in the member information models. The design, construction, environmental condition, painting, and bridge parameters are maintained as subclasses.

4.5. Construction of Business Data Models. The business data model is composed of input and output data in the maintenance process. The required functions of input data are analyzed from the viewpoints of utilization of information, cost reduction, and operations reduction. In the viewpoint of cost reduction, the functions are extracted for reducing the maintenance costs. In the viewpoint of utilization of information, the functions are extracted for utilizing the inspection and assessment results about the soundness information. In the viewpoint of operations reduction, the functions are extracted for reducing the existing operations. The extracted functions are used for defining and modeling the results, the attributes of information, and the relation of information. The input data of member data models is defined by the accumulated business and member information. The input data is extracted on the member data models in the case of comprehending the condition of members and the future prospects.

The required functions of output data are analyzed from the viewpoints of comprehension of member soundness and accumulation of deterioration condition in members. In the viewpoint of comprehension of member soundness, the functions are extracted for making a decision of business. The information accumulates the results of maintenance plan, inspection plan, deterioration assessment, and judgment of soundness. In the viewpoint of accumulation of deterioration condition in members, the functions are extracted for accumulating the information of member condition. The output data of business data models is accumulated in the member data models and maintains the attributes of members. The attributes have the date and hour of inspection and repair, damage condition, and prediction of deterioration. The results of inspection, assessment, repair, and reinforcement are accumulated in the member data models.

The member and business data models are encoded by XML. Bridge engineers can acquire the input data of business data models and can accumulate the results in the member data models. The product data models are useful for exchanging, accumulating, and utilizing the standardized maintenance information in any bridge management system.

\section{Utilization Platform of Product Data Models}

In this section, the business flow using product data models is expressed as the utilization scenario. And, the utilization system that expressed information flow for realizing the utilization scenario is defined in chronological order.

5.1. Utilization Scenario of Product Data Models. The utilization scenario of product data models is constructed for realizing the following three points.

(1) Maintenance and inspection plans are instituted from a long-term aspect by using the inspection and deterioration assessment information.

(2) The accuracy of deterioration assessment and soundness evaluation is secured in consideration of temporal changes.

(3) The overlapping operations are reduced by the utilization of information.

This paper proposes the utilization scenario based on project management and preventive maintenance. Figure 6 shows the utilization scenario of product data models. The agency comprehends the national demands and decides trustee of maintenance on considering the budget. The project manager receives the maintenance. The agency checks the quality of results in maintenance work. In the utilization scenario, the features are described as follows.

(1) The project manager executes initial inspection for planning the maintenance plan based on the soundness of members.

(2) The project manager forecasts the deterioration before planning the maintenance plan and decides the maintenance division by each member referring to the results of initial inspection.

(3) The bridge manager assesses the deterioration after daily inspection and regular inspection. In the deterioration diagnosis, the deterioration mechanism is decided by classifying the deterioration phenomenon and presuming the deterioration factors. When the members deteriorate significantly, detailed inspection is executed for gathering the information to judge the necessity of repair and reinforcement.

(4) The project manager evaluates the soundness of members and forecasts the deterioration by using initial inspection, detailed inspection, and soundness evaluation results after detailed inspection. 


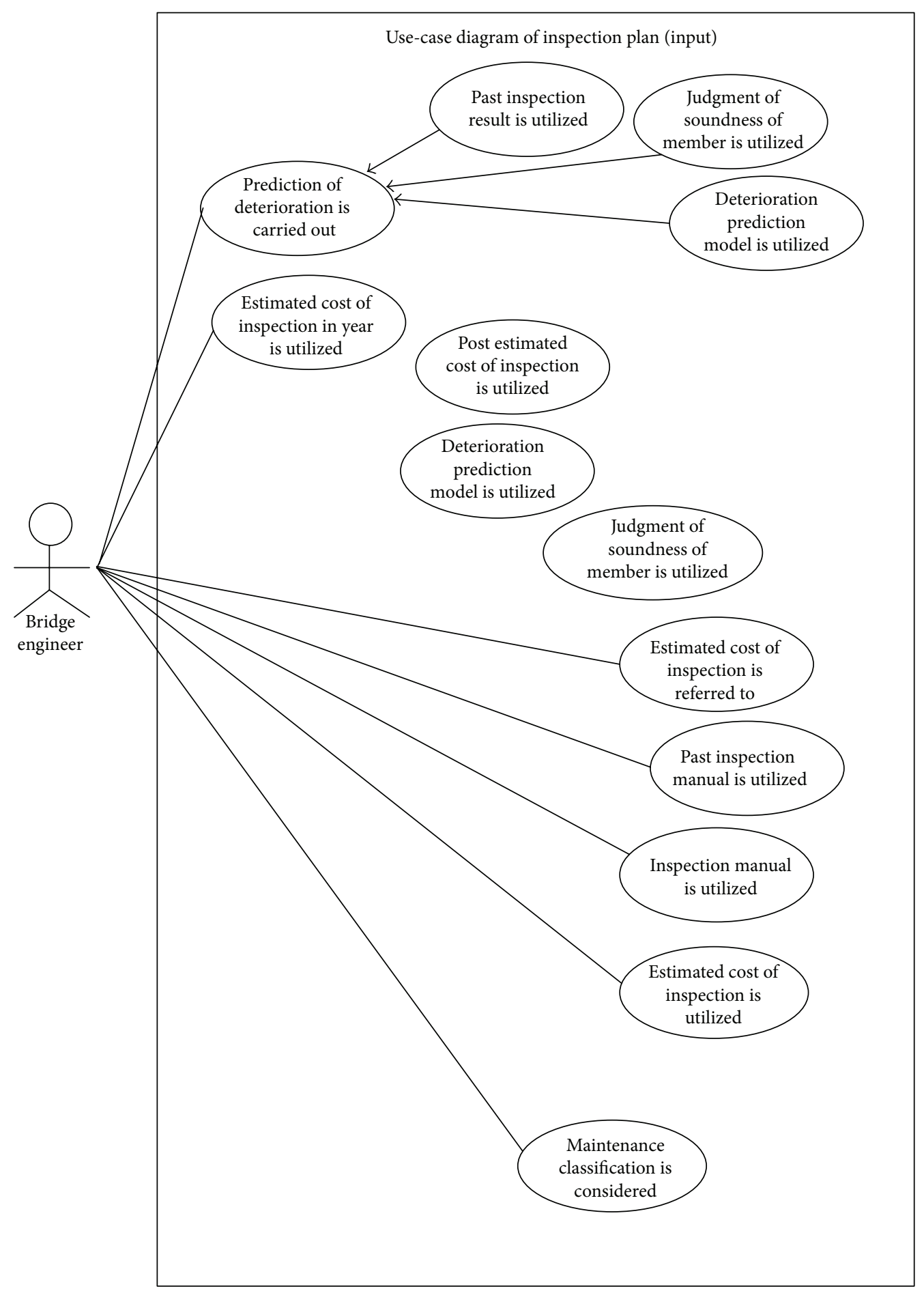

FIGURE 4: Required function of input data of inspection plan.

5.2. Utilization System of Product Data Models. The utilization system is constructed, which expresses the information flow in chronological order for realizing the utilization scenario. The historical information based on the data models is accumulated from inspection to repair and reinforcement consistently. It is utilized in soundness evaluation, deterioration diagnosis, and deterioration forecast. Therefore, the maintenance, inspection, and repair/reinforcement plans are formulated by using soundness of members comprehended with accuracy. The utilization system of product data models in initial inspection is shown in Figure 7. The system supporting the initial inspection has roles in deciding the inspection methods and items and accumulating the inspection results. Project manager decides the inspection methods and items 


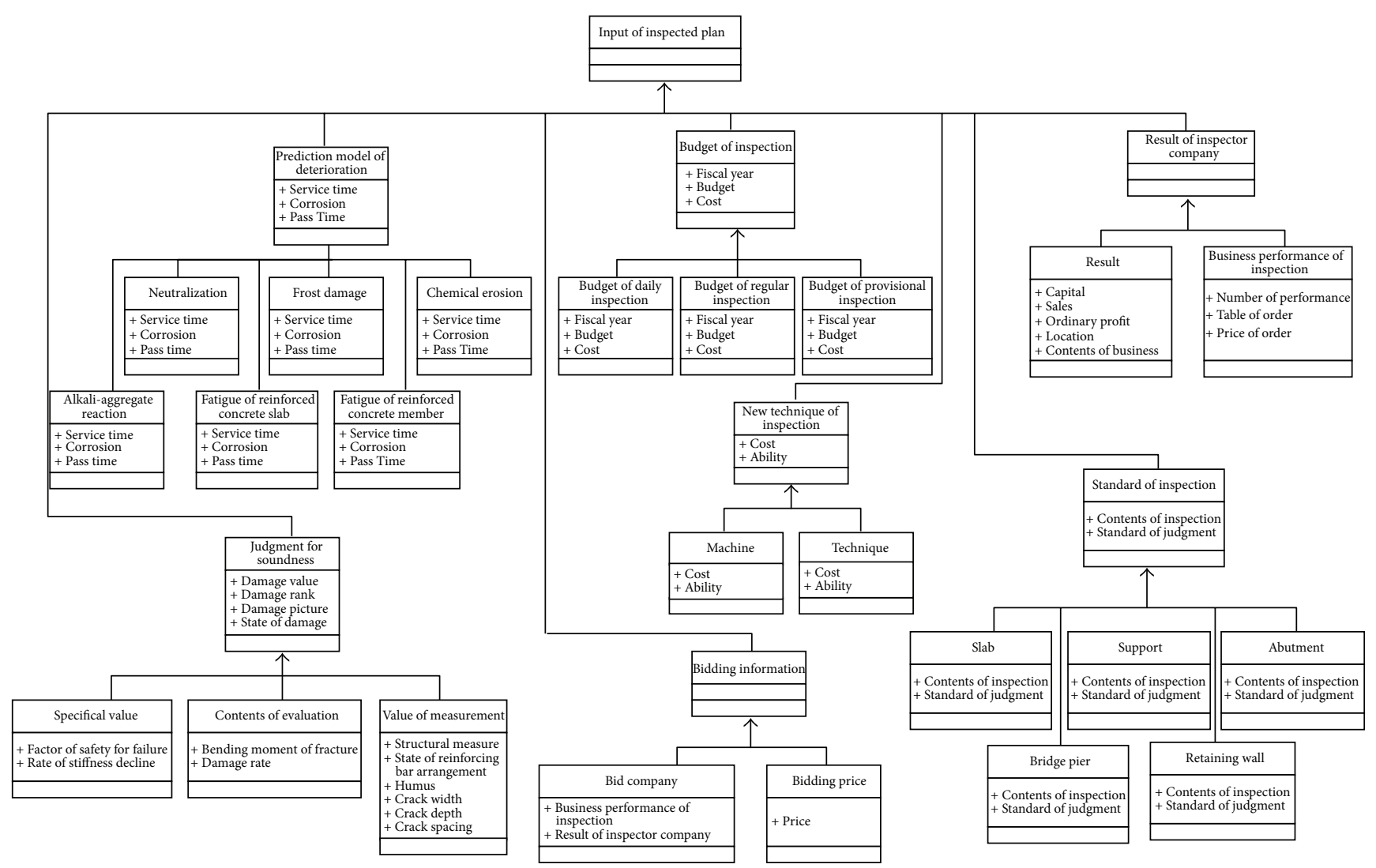

FIgURE 5: Data model of inspection plan.

by using the inspection manual, design information, and construction information and selects inspector referring to the inspection results. Inspector inspects the initial breakages in accordance with inspection method and items and reports and accumulates the results.

The utilization systems of product data models are constructed in a similar way of initial inspection, which are inspection plan, maintenance plan, inspection, deterioration diagnosis, detailed inspection, judgment of necessity on repair and reinforcement, repair and reinforcement plan, and repair and reinforcement.

5.3. Evaluation of Process Model. The constructed process model is evaluated for validating the availability that the process model solves the issues of as-built process.

(1) [As-built]: Bridge manager designs maintenance plan based on symptomatic treatment that is treated symptoms as damages appear. The symptomatic treatment invokes the breakage in the same members.

[As-built]. In maintenance plan, deterioration prediction information is not used. Bridge manager does not understand historical change of members and treats symptoms as damages appear.

[To-be]. Deterioration is predicted in maintenance plan. Maintenance plan is formulated based on the results of deterioration prediction from long-term perspective.

(2) [As-built]. The engineers refer the structure elements lists and bridge ledgers redundantly in maintenance planning corresponding to inspection planning.

[To-be]. The engineers refer to the structure, design information, and construction information in the bridge elements lists and the bridge ledgers for maintenance planning and decide the maintenance classification. The inspection time and inspection frequency are decided. Therefore, the overlapped operations are reduced.

(3) [As-built]. The engineers do not use the past results of soundness evaluation and deterioration prediction for comprehending the soundness of members. The judgement of necessity of follow-up review depends on the engineer skill.

[To-be]. The deterioration is diagnosed based on the daily and regular inspections. The results of inspections and soundness evaluation, design information, and construction information are utilized based on the proposed information models.

(4) [As-built]. The engineers refer to the maps, bridge ledgers, bridge elements, and inspection manuals in follow-up review corresponding to detailed inspection. 


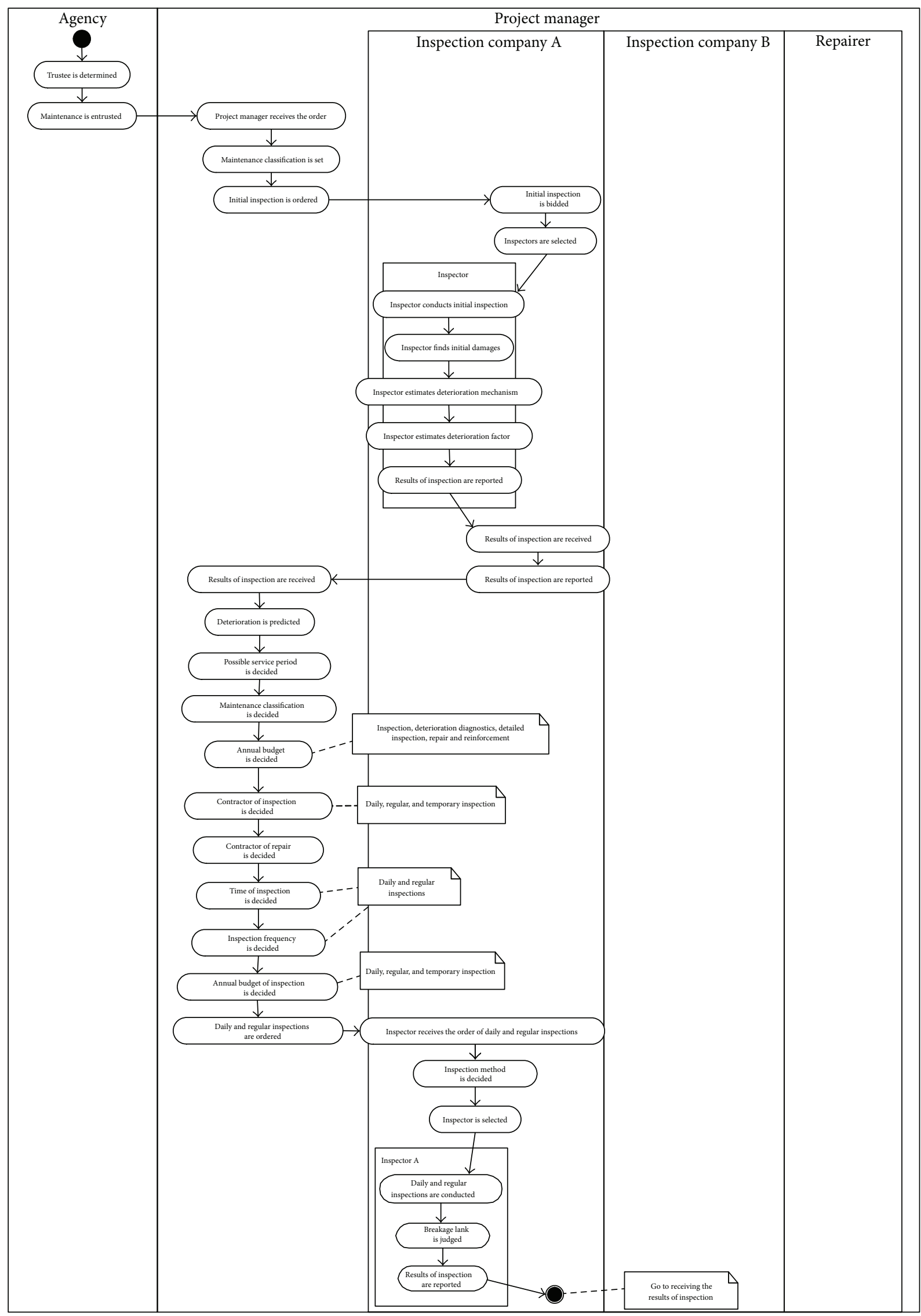

(a)

Figure 6: Continued. 


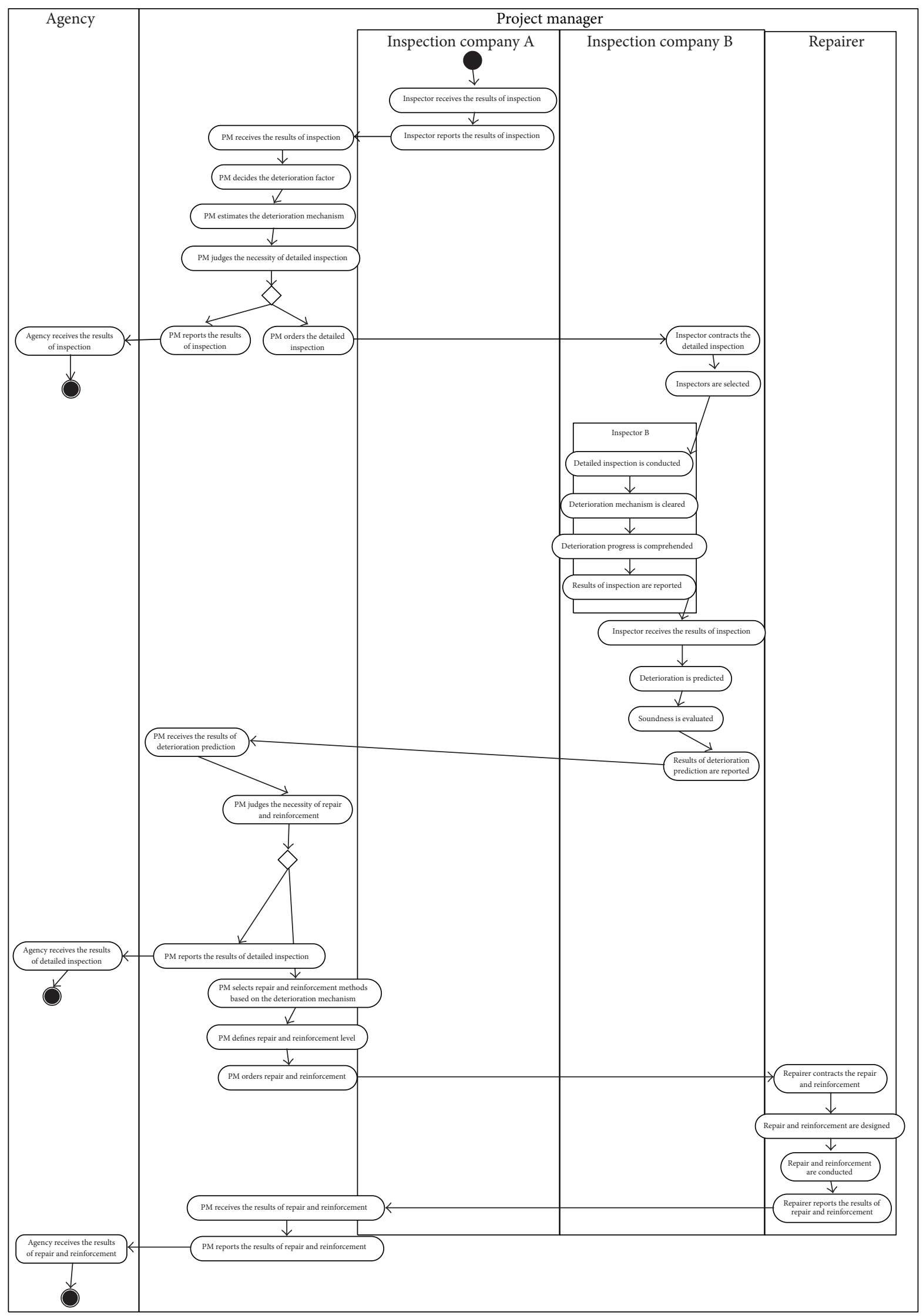

(b)

Figure 6: (a) Proposed maintenance flow as utilization scenario (1). (b) Proposed maintenance flow as utilization scenario (2). 


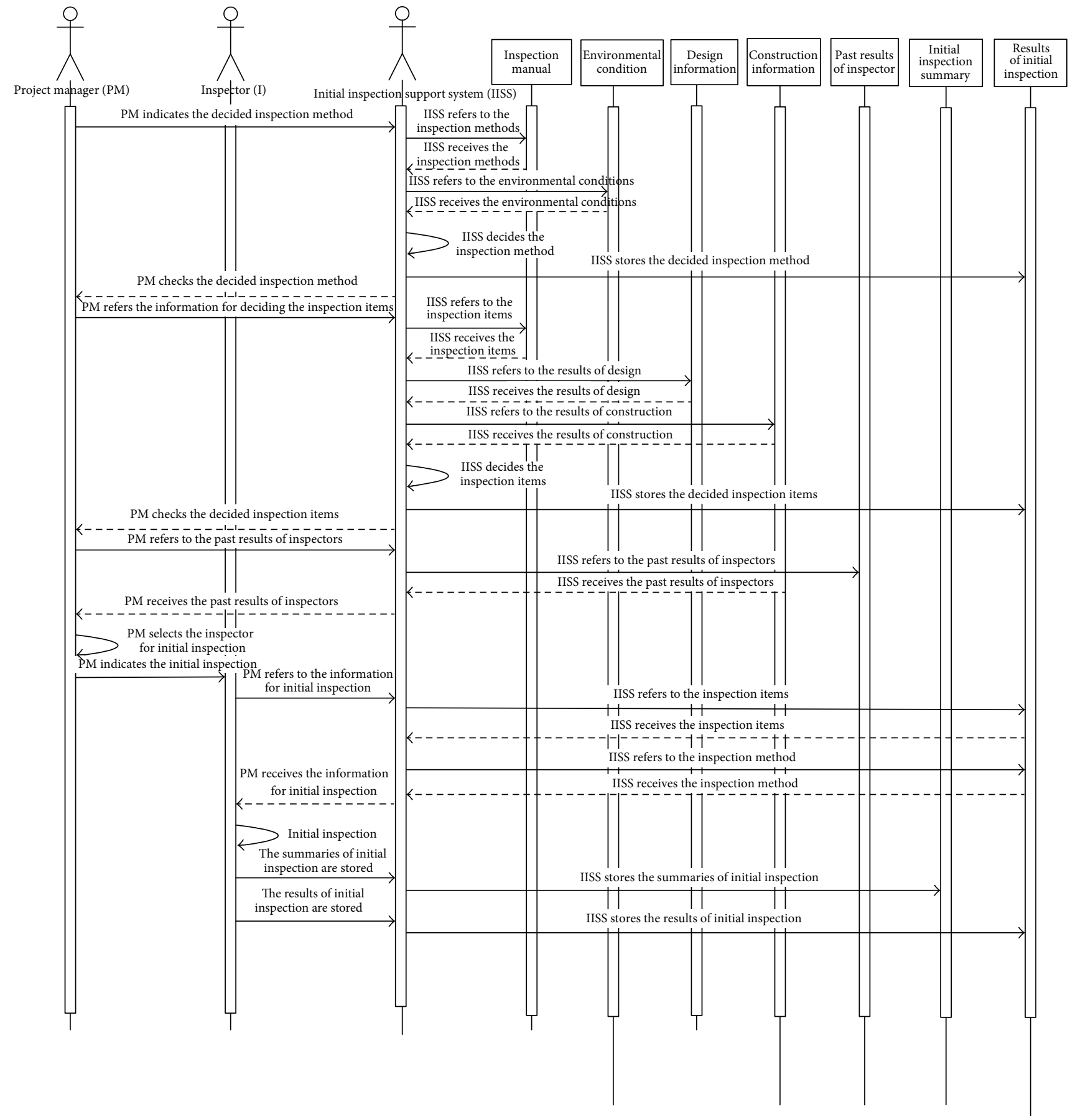

FIGURE 7: The utilization system of product data models in initial inspection.

[To-be]. The bridge manager diagnoses the deterioration based on the results of daily and regular inspections. The follow-up review which collects the results for comprehending the soundness is cut off by diagnosing the deterioration.

(5) [As-built]. The engineers do not use the results of past renewal judgements and deterioration diagnostics for judging the renewal. The accuracy of renewal judgement depends on the engineer skill.

[To-be]. The deterioration mechanism is decided on considering deterioration progress in the judgement of necessity of repair and reinforcement. The results are useful for forecasting the deterioration. The time of repair and reinforcement becomes appropriate.

\section{Conclusions}

In the present paper, the product data models are constructed for improving the efficiency of maintenance. The product data models are useful for exchanging, accumulating, and utilizing the standardized maintenance information. The process model is constructed based on the ideas of project management and preventive maintenance. The ideas are used for 
systematizing the maintenance flow. The utilization method of product data models is defined in temporal sequence. The constructed process model was evaluated for validating the availability. The maintenance engineers can maintain the concrete highway bridges by following the proposed utilization platform.

This research is a part of a large research project. The authors have constructed STEP-based product data model, geospatial data model, and product data model-based information management system [29]. The system was developed for collecting, storing, controlling, sharing, and using maintenance data by using database based on product data model. This research project will be a framework that can be applied to road maintenance management, disaster management, construction management, and web collaboration with project participants.

\section{References}

[1] H. Seki, "Research activities on maintenance of concrete structures," Journal of Materials, Concrete Structures and Pavements, vol. 557, no. 5-34, pp. 1-14, 1997 (Japanese).

[2] Ministry of Land, Infrastructure and Transport (MLIT), Proposal of Concept in Maintenance and Renewal of Road Structures, 2003 (Japanese).

[3] O. Abudayyeh and H. T. Al-Battaineh, "As-built information model for bridge maintenance," Journal of Computing in Civil Engineering, vol. 17, no. 2, pp. 105-112, 2003.

[4] P. D. Thompson, J. O. Sobanjo, and R. Kerr, "Florida DOT project-level bridge management models," Journal of Bridge Engineering, vol. 8, no. 6, pp. 345-352, 2003.

[5] A. Stein, "OKSTRA - the key to road and transport data foundations for a road information system," in Proceedings of the Asia GIS 2001, 2001.

[6] Ministry of Land, Infrastructure and Transport (MLIT), Bridge Inspection Procedure, 1993 (Japanese).

[7] Japan Highway Public Corporation, Maintenance Procedure, 1999 (Japanese).

[8] Metropolitan Expressway Public Corporation, Structures Inspection Procedure, 2001 (Japanese).

[9] Hanshin Expressway Public Corporation, Inspection Standards of Road Structures, 1996 (Japanese).

[10] A. L. Stumpf, R. Ganeshan, S. Chin, and L. Y. Liu, "Objectoriented model for integrating construction product and process information," Journal of Computing in Civil Engineering, vol. 10, no. 3, pp. 204-212, 1996.

[11] A. Karim and H. Adeli, "OO information model for construction project management," Journal of Construction Engineering and Management, vol. 125, no. 5, pp. 361-367, 1999.

[12] J. Hastings, J. Kibiloski, M. Fischer, J. Haymaker, and K. Liston, "Four-dimensional modeling to support construction planning of the stata center project," Leadership and Management in Engineering, vol. 3, no. 2, pp. 86-90, 2003.

[13] K. W. Chau, M. Anson, and J. P. Zhang, "Four-dimensional visualization of construction scheduling and site utilization," Journal of Construction Engineering and Management, vol. 130, no. 4, pp. 598-606, 2004.

[14] T. A. Ei-Diraby, C. Lima, and B. Feis, "Domain taxonomy for construction concepts: toward a formal ontology for construction knowledge," Journal of Computing in Civil Engineering, vol. 19, no. 4, pp. 394-406, 2005.
[15] A. Owolabi, C. J. Anumba, A. El-Hamalawi, and C. Harper, "Development of an industry foundation classes assembly viewer," Journal of Computing in Civil Engineering, vol. 20, no. 2, pp. 121131, 2006.

[16] M. M. R. Halfawy and T. M. Froese, "Component-based framework for implementing integrated architectural/ engineering/ construction project systems," Journal of Computing in Civil Engineering, vol. 21, no. 6, pp. 441-452, 2007.

[17] I. Mikami, S. Tanaka, S. Kubota, and Y. Ishii, "Visualization of product data models for highway bridges using VRML", in Proceedings of the 7th East Asia-Pacific Conference on Structural Engineering \& Construction, pp. 584-589, 1999.

[18] I. Mikami, S. Tanaka, S. Kubota, and Y. Ishii, "Database of highway bridges' product data models using STEP," in Proceedings of the 7th East Asia-Pacific Conference on Structural Engineering \& Construction, pp. 590-595, 1999.

[19] S. Kubota and I. Mikami, "To-be information models for maintenance of concrete highway bridges," in Proceedings of the 10th International Conference on Civil, Structural and Environmental Engineering Computing, B. H. V. Topping, Ed., Civil-Comp Press, Stirling, UK, September 2005.

[20] K. Monobe and S. Kubota, "A proposal of 3D product data model and its application system for civil infrastructure," in Proceedings of the 1st International Conference on Sustainable Urbanization, 2010, BIM17_ICSU10468.

[21] S. Kubota, "Distribution and utilization of three-dimensional life-cycle information on civil infrastructure in Japan," International Journal of Social Science and Humanity, vol. 2, no. 1, pp. 24-29, 2012.

[22] N. Yabuki, E. Lebegue, J. Gual, T. Shitani, and Z. Li, "International collaboration for developing the bridge product model "IFC-BRIDGE"', in Proceedings of the Joint International Conference on Computing and Decision Making in Civil and Building Engineering, pp. 1927-1936, Montreal, Canada, 2006.

[23] CityGML, 2013, http://www.citygmlwiki.org/index.php/CityG ML_Bridge_ADE.

[24] T. Hartmann, J. Gao, and M. Fischer, "Areas of application for 3D and 4D models on construction projects," Journal of Construction Engineering and Management, vol. 134, no. 10, pp. 776785, 2008.

[25] M. Fischer and C. Kam, "Product model and 4D CAD: final report," Tech. Rep. 143, Center for Integrated Facility Engineering, 2002.

[26] S. Staub-French and A. Khanzode, "3D and 4D modeling for design and construction coordination: issues and lessons learned," Electronic Journal of Information Technology in Construction, vol. 12, pp. 381-407, 2007.

[27] B. Koo and M. Fischer, "Feasibility study of 4D CAD in commercial construction," Journal of Construction Engineering and Management, vol. 126, no. 4, pp. 251-260, 2000.

[28] J. Park, B. Kim, C. Kim, and H. Kim, "3D/4D CAD applicability for life-cycle facility management," Journal of Computing in Civil Engineering, vol. 25, no. 2, pp. 129-138, 2011.

[29] S. Kubota and I. Mikami, "4D information management system for road maintenance using GIS," in Proceedings of the International Conference on Computing in Civil and Building Engineering, W. Tizani, Ed., Nottingham University Press, Nottingham, UK, 2010, paper 58. 

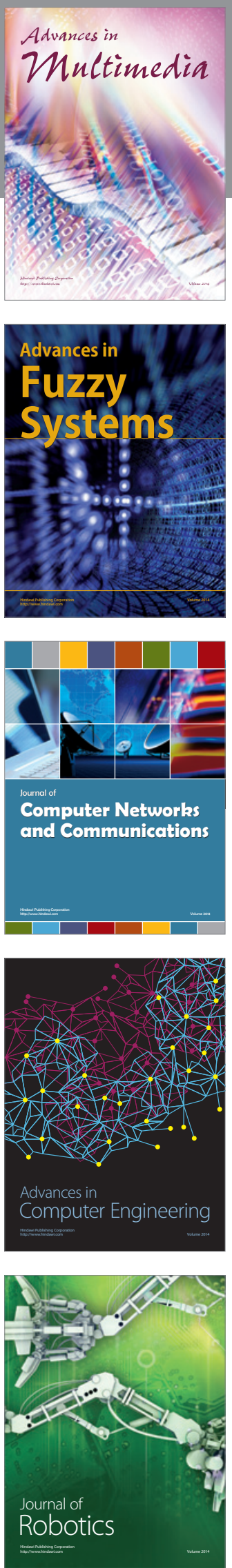

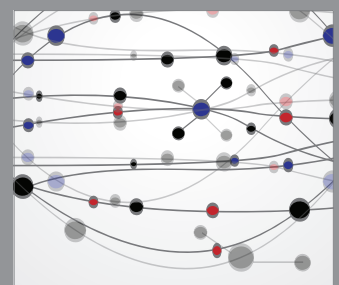

The Scientific World Journal
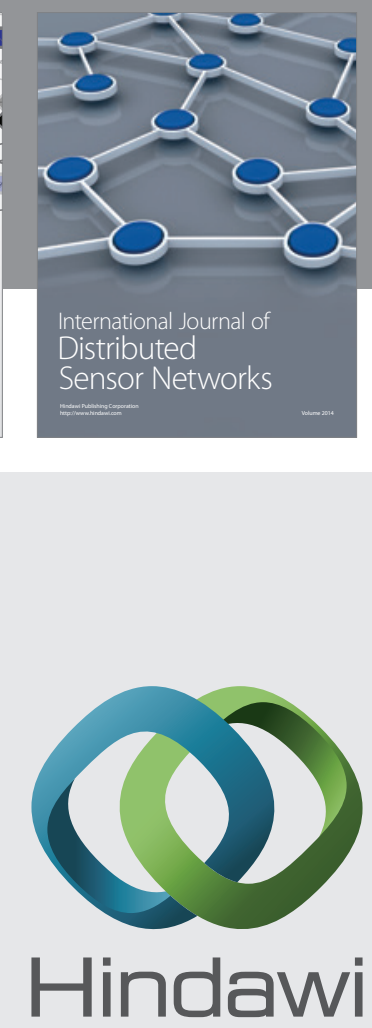

Submit your manuscripts at

http://www.hindawi.com
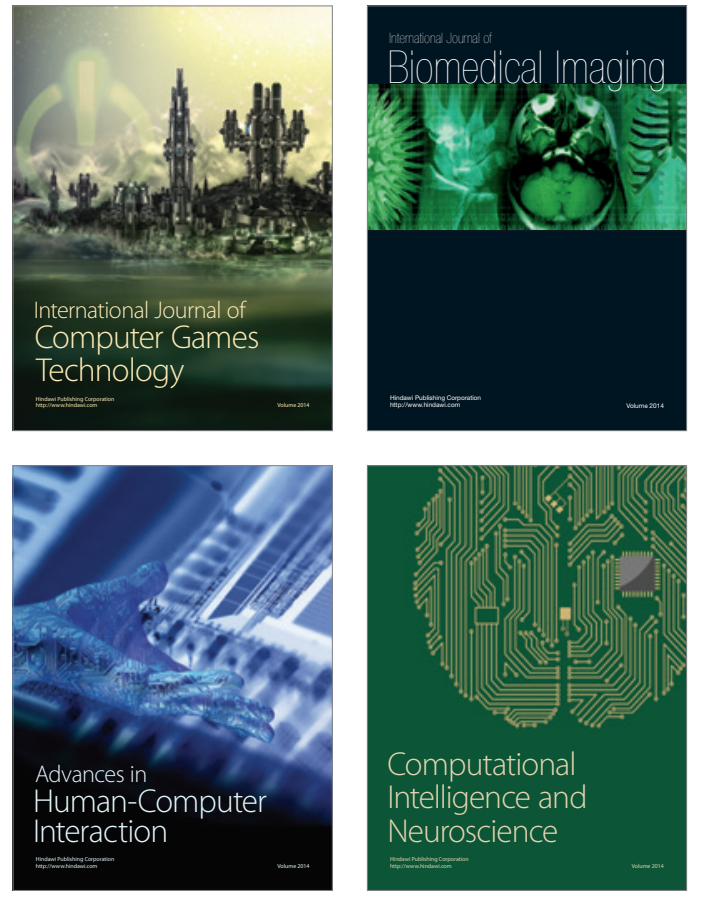
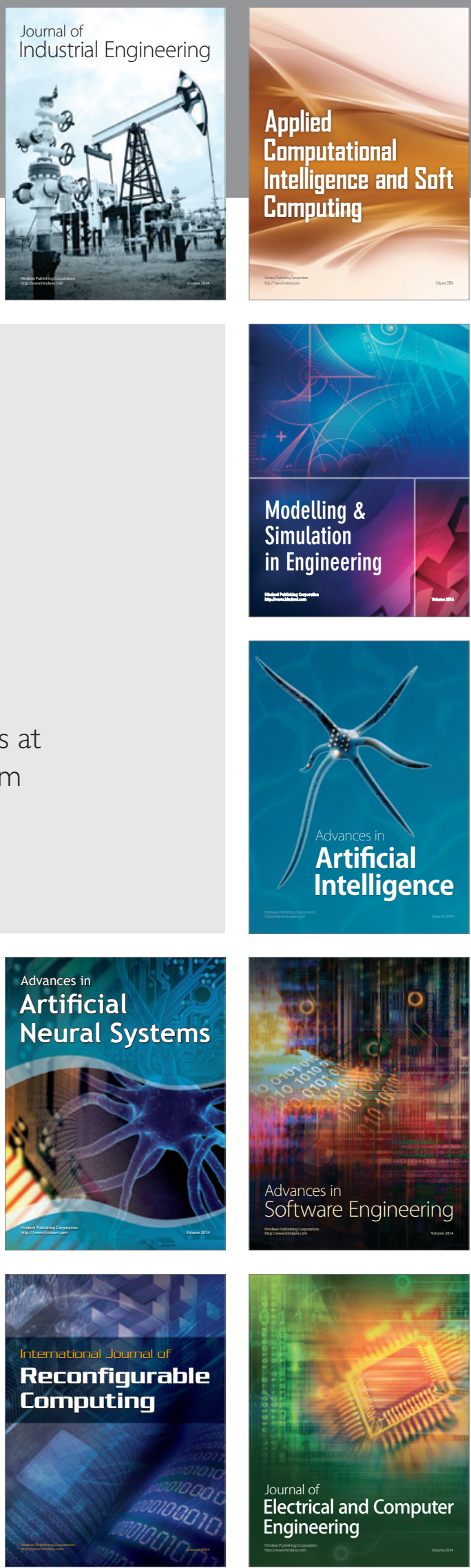